\title{
Lutos e lutas: Reestruturações familiares diante do câncer em uma criança/adolescente
}

\author{
Mournings and struggles: Family reestructuring \\ following cancer in a child/adolescent
}

\section{Alberto Manuel Quintana ${ }^{[a]}$, Shana Hastenpflug Wottrich ${ }^{[b]}$, Valéri Pereira Camargo ${ }^{[c]}$, Evandro de Quadros Cherer ${ }^{[\mathrm{d}]}$, Paula Kieling Ries ${ }^{[\mathrm{e}]}$}

[a] Psicólogo, Doutor em Ciências Sociais (Antropologia Clínica), professor do Curso de Psicologia e dos Programas de Pós-Graduação em Psicologia (Mestrado) e Enfermagem (Mestrado) da Universidade Federal de Santa Maria (UFSM), Santa Maria, RS - Brasil, e-mail: albertom.quintana@gmail.com

[b] Mestranda do Programa de Pós-Graduação em Psicologia da Universidade Federal de Santa Maria (UFMS), Bolsista CAPES (Demanda Social), Psicóloga Especialista em Cardiologia, Santa Maria, RS - Brasil.

[c] Acadêmica de Psicologia da Universidade Federal de Santa Maria (UFSM), Santa Maria, RS - Brasil.

[d] Acadêmico de Psicologia da Universidade Federal de Santa Maria (UFSM), Santa Maria, RS - Brasil.

[e] Médica oncologista pediátrica do Hospital Universitário de Santa Maria (UFSM), Santa Maria, RS - Brasil.

\section{Resumo}

Este trabalho retrata um recorte de resultados de um estudo exploratório/descritivo, de abordagem qualitativa. Visa a compreender qual é a significação que os pais/cuidadores de crianças diagnosticadas com câncer atribuem às relações entre esse diagnóstico e a sua dinâmica familiar. Foram utilizadas técnicas de entrevistas semiestruturadas e grupos de discussões, constituídos por pais/ cuidadores, acompanhantes das crianças e adolescentes durante a internação em um hospital público. O número de participantes da pesquisa foi definido a partir de critérios de saturação da amostra e os dados coletados foram transcritos na íntegra e analisados a partir da análise de conteúdo. As categorias e subcategorias emergentes foram: Casa x Hospital; Mudanças e Desestruturação Familiar; Papel Materno; As Mães na Sala e suas InterRelações (Identificação e Competição como subcategorias); Rede de Apoio (tendo como subcategorias Papel Paterno, Filhos Sem o Diagnóstico de Câncer e Demais Amigos, Parentes). Neste estudo, destaca-se o papel materno como o que mantém e assegura a coesão familiar e a integridade dos filhos, tanto psíquica quanto física. A responsabilização por tal integridade, mediante a situação de doença, parece 
gerar carga intensa de sofrimento. Apesar do conhecimento do senso comum de que a doença é algo que diz respeito à ordem do incontrolável, ainda assim, para os entrevistados, parece haver um esforço no sentido de exercer controle sobre a situação de adoecimento. Diante da impossibilidade disso, emergem, além dos sentimentos de impotência e culpa, situação de sobrecarga implicada na posição onipotente em que se coloca o cuidador principal, culminando no sentimento de desamparo.

Palavras-chave: Criança. Adolescentes. Família. Psicologia da saúde.

\begin{abstract}
This paper portrays some results of an exploratory/descriptive study, of qualitative approach. It aims to understand what meaning parents/caregivers of children with cancer diagnosis attribute to the relations between such diagnosis and the family dynamics. Semi-structured interviews and discussion groups were accomplished, and were constituted by parents/caregivers who were together with the children/adolescents during their in-hospital experience in a public hospital. The number of participants was defined by sample saturation criteria and data collected were transcribed and analyzed through content analysis. The emerging categories and subcategories are as follows: Home X Hospital; Changes and Family Lack of Structuring; Maternal Role; Mothers in the Ward and theirs Inter-Relations (Identification and Competition as subcategories); Support Network (and its subcategories, namely Paternal Role; Children without Cancer Diagnosis and Other Friends, Relatives). This study highlights the role of the mother as she plays an important part regarding the assurance of family cohesion and children integrity, both physical and psychological. Taking responsibility for such integrity in such situation seems to cause intense psychological overload and suffering. Besides common sense knowledge that disease is uncontrollable, yet, the interviewed subjects seem to make efforts to be in control of the disease. Beyond the feelings of impotence and guilt, there seems to be a psychological overload from the omnipotent role played by the primary caregiver, generating feelings of despair, since such control is not possible.
\end{abstract}

Keywords: Child. Adolescents. Family. Health psychology.

\section{Introdução}

Desde o momento da sua concepção até o momento da sua morte, o ser humano atravessa processos complexos de desenvolvimento, sendo o período da infância, entretanto, o tempo no qual as mudanças e crescimentos ocorrem mais ampla e rapidamente (Papalia, 2006). A infância é uma fase de descobertas, de novos amigos e brincadeiras, é um momento muito intenso em que a criança passa a experimentar o mundo sobre o atento olhar dos pais ou cuidadores.

Há, no entanto, fatores que podem interferir nesse processo de desenvolvimento infantil saudável. O diagnóstico de câncer é um desses fatores, e, além de afetar a saúde da criança diagnosticada, acaba por adoecer todo seu círculo familiar (Valle \& Françoso, 1999). O câncer caracteriza-se por ser um grupo de doenças que causa o crescimento desordenado e maligno de células, invadindo os tecidos e órgãos e podendo espalhar-se (metástase) para outras regiões do corpo (Instituto Nacional de Câncer - INCA, 2008). Segundo a Organização Mundial de Saúde(OMS, 2008), o cânceré a segunda enfermidade que mais mata no mundo, perdendo apenas para os problemas cardíacos. O câncer infantil, especificamente, tem obtido um aumento progressivo e linear (INCA, 2008), caracterizando-se como patologia crônica, tendo como consequência a exigência de um tratamento longo e exaustivo, caracterizado por procedimentos intrusivos (Valle \& Mello, 1999), realizados, com frequência, em ambiente hospitalar.

Sabe-se que a hospitalização traz implicações subjetivas importantes. Angerami-Camon (2006) destaca, dentre as reações à hospitalização, a situação de despersonalização do paciente. Tal contingência teria como consequência uma espécie de desestruturação subjetiva, visto que o paciente passa de "sujeito deintenções" a "sujeito de atenções" (Botega, 2006). Dessa forma, o doente seria colocado em situação passiva frente aos fatos e perspectivas existenciais, deixando de ter significado próprio para representar 
a si mesmo, a partir de diagnósticos e procedimentos médicos (Angerami-Camon, 2006). Entende-se que esse cenário de desconsideração da subjetividade do indivíduo tende a ser ainda mais acentuado quando se trata da situação de adoecimento de uma criança, posto que o seu adoecimento implica também no adoecimento da família (Chiattone, 2003a).

Os componentes do grupo familiar, ao se interrelacionarem afetivamente configuram um sistema dinâmico onde cada fator novo, como um nascimento, uma morte ou diferenças na rotina, são capazes de provocar mudanças estruturais. Dessa forma, o surgimento de uma doença em qualquer um dos membros do grupo familiar, vai provocar uma reorganização e distribuição de papéis (Kovács, 2003; Quintana, Arpini, Pereira \& Santos, 2009).

Posto isso, contrariamente ao cotidiano familiar, o papel da família enquanto cuidadora na internação hospitalar passa a ser compartilhado, pois é da equipe a responsabilidade por alguns dos cuidados anteriormente identificados como funções da família. Nesse sentido, pode haver um sentimento de impotência e perda de controle (Bousso \& Angelo, 2001; Chiattone, 2003b; Silva, Weiss, Bernardes \& Souza, 2006). Assim, a inclusão da família no espaço hospitalar faz com que ela vivencie vários desafios para os quais não está preparada (Quintana et al., 2009). Tais desafios dizem respeito ao contato com um mundo de linguajar específico, de limites institucionais no que se refere a sua autonomia na tomada de decisões, de normas e rotinas diferentes de seu cotidiano (Silva et al., 2006).

O familiar, ao se tornar cuidador, tem sua vida afetada em vários aspectos, como interferências no trabalho e em sua vida pessoal (Wanderbroocke, 2005), impondo a necessidade de refazer expectativas e de redimensionar planos futuros. As atividades do cotidiano familiar são re-estruturadas, havendo mudanças no âmbito social e financeiro. Nesse sentido, não é raro o rompimento do vínculo empregatício de um dos cuidadores, em geral a mãe (Silva, Andrade, Barbosa, Hoffmann \& Macedo, 2009), o que acarreta sobrecarga na esfera da organização econômica familiar (Ortiz \& Lima, 2007). Há um cenário que envolve completa dedicação aos filhos doentes, configurando-se a partilha de sofrimentos e lutas vivenciados. A vida dos familiares/cuidadores, assim, passa a ser re-significada meio a sentimentos e vivências ambivalentes, que ora remetem à vida $\mathrm{e}$ ora remetem à morte (Monteiro, Veloso, Sousa \& Morais, 2008).

Conforme Wanderbroocke (2005), são as mulheres que mais frequentemente assumem os papéis de cuidadoras principais, dedicando mais tempo à pessoa doente e assumindo as tarefas vinculadas ao manuseio com o corpo. Assim, em grande parte das situações de doença, a mãe é quem acompanha os filhos de forma mais próxima em seus tratamentos e internações. Por ter como função primária a alimentação dos filhos através da amamentação, pode-se pensar que as repercussões do tratamento que envolvem tal questão causem ansiedade. Dessa maneira, incomoda às mães a ausência de apetite nos filhos causada pelo tratamento (Beck \& Lopes, 2007b). Tal cenário pode, de forma fantasiosa, incrementar o sentimento de culpa, na medida em que a doença impede que a mãe desempenhe a sua função mais primitiva - a nutrição do filho.

Aparece, ainda, a responsabilização materna de forma proeminente, de forma a gerar dificuldades na delegação de funções para outras pessoas, tanto em relação aos cuidados hospitalares, quanto em relação às tarefas da vida doméstica e, em certos casos, ao trabalho. Apresenta-se a crença de que ninguém está à altura da mãe para cuidar e proteger seu filho (Beck \& Lopes, 2007b). Sob essa perspectiva, as mães podem acabar gerando um movimento de sobrecarga para si mesmas, impossibilitando uma divisão mais equitativa de papéis e condições deletérias em termos de qualidade de vida também vinculadas ao sono (Beck \& Lopes, 2007a; Silva et al., 2009) e lazer (Beck \& Lopes, 2007a). Há, portanto, uma atmosfera de tensão intensa em decorrência do papel de cuidador. Tal tensão pode estar associada à gravidade da doença do receptor de cuidados, falta de descanso ou recreação para o cuidador ou recreação insuficiente (Beck \& Lopes, 2007b)

As implicações em relação às mudanças da rotina do casal incluem conflitos matrimoniais (Chiattone, 2003b) e consequências para o relacionamento sexual do casal (Beck \& Lopes, 2007a). O cuidador principal espera que o outro o compreenda em sua posição de dedicação total ao filho (Beck \& Lopes, 2007b). Assim, a desestruturação familiar inicia pelo desequilíbrio da relação na unidade conjugal, através do rompimento dos laços afetivos entre o casal a fim de dedicarem-se exclusivamente ao filho (Silva et al., 2009). 
Conforme Chiattone (2003b) há uma mudança de papéis na estrutura familiar para dar conta dos cuidados. Essas mudanças podem implicar em distanciamento entre os integrantes da família, incluindo inclusive repercussões que se referem aos filhos saudáveis (Monteiro et al., 2008; Ortiz \& Lima, 2007; Quintana et al., 2009). Geralmente enquanto a mãe permanece no hospital com o paciente, o irmão sadio fica afastado, permitindo o surgimento do sentimento de exclusão durante o tratamento e afastamento familiar (Pedrosa \& Valle, 2000). Essa divisão da família, devido às exigências impostas pelo tratamento, pode promover uma sensação de perda da filiação, uma vez que os pais tendem a sentirem-se responsáveis pela coesão familiar. Tal condição gera a sensação de impotência e o sentimento de que os cuidadores estão sendo negligentes e irresponsáveis (Crepaldi, 1998). Observa-se que a falta de atenção aos filhos não é apenas cobrada por aqueles que permanecem em ambiente domiciliar, mas também é sentida pela própria mãe, acentuando o sentimento de culpa (Klassmann, Kochia, Furukawa, Hiragashi \& Marcon, 2008).

As reações do filho saudável à realidade da doença do irmão são variadas, havendo relatos da presença de solidariedade, ciúmes e desprezo (Silva et al., 2009). Deve-se levar em consideração em relação ao filho sadio a falta de coesão familiar promovida pelas ausências dos pais durante a doença do irmão, a deficiência de comunicação e a presença de fantasias. A culpa em função do adoecimento da criança pode gerar comportamentos compensatórios por parte dos familiares/cuidadores, gerando atitude de superproteção (Bousso \& Angelo, 2001; Chiattone, 2003b). Assim, recomendações e cuidados especiais cercam o filho enfermo através do excesso de zelo dos pais, podendo provocar ciúmes, ressentimento e inveja no filho saudável. Para o irmão do enfermo não é de fácil elaboração ter de assimilar tantas novas mudanças na família que exigem seu amadurecimento e ainda estar sujeito a "indiferença" dos pais. Dessa forma, o câncer pode ser percebido como fonte de ganhos secundários, acabando por gerar o desejo de ter os cuidados paternos dedicados ao irmão doente. Enfim, os irmãos vivem numa ambiguidade entre a compreensão das necessidades do paciente e os sentimentos de abandono e ciúmes (Pedrosa \& Valle, 2000).

Problemas de relacionamento podem ser incrementados como aparecimento da doença na família (Chiattone, 2003b), e, por outro lado, ser um evento de união e reconciliação em algumas famílias (Beck \& Lopes, 2007a, Chiattone, 2003b). Nesse sentido, Bousso e Angelo (2001) destacam a existência de um movimento de busca de preservação da integridade familiar diante da crise representada pelo adoecimento. Há a estruturação de estratégias para manter a união familiar, buscando evitar conflitos e oferecer apoio recíproco. No âmbito da família, os suportes informais mostram-se nos aspectos afetivo e em relação às tarefas domésticas (Beck \& Lopes, 2007a).

Os cuidadores também podem procurar suporte em outras famílias que estão vivendo situações semelhantes, através de processos identificatórios e de conformação de espaço de expressão de sentimentos e de reflexão. Além disso, há relatos de situações em que o suporte acontece por meio de amigos, equipe de saúde e religião (Ortiz \& Lima, 2007). A relação entre as famílias de doentes oncológicos permite, por vezes, o estabelecimento de uma relação autêntica de cuidado que facilita o tratamento (Monteiro et al., 2008).

Ainda, tal realidade é matizada por outros conteúdos na medida em que se considera o contexto da doença oncológica. Em tal âmbito, além do medo da morte, perda e aniquilação física e psíquica, há a separação física decorrente dos isolamentos e deslocamentos frequentes em busca de tratamentos mais avançados (Menezes, Passareli, Drude \& Santos, 2007). Outras características do tratamento oncológico referem-se à necessidade de reinternações frequentes, terapêutica agressiva, efeitos colaterais causadores de sofrimento físico e psíquico (Klassmann etal., 2008; Nascimento, Rocha, Hayes \& Lima, 2005).

Os sentimentos que os familiares experimentam após o anúncio do diagnóstico do câncer e até mesmo na etapa pré-diagnóstica, se relacionam com o que é apontado pela literatura como um processo de luto antecipatório (Parkes, 1998). O mesmo refere-se não só a possibilidade de uma morte física, mas também faz referência às várias modificações estruturais que a doença e tratamento impõem. Esses lutos podem dizer respeito à profissão que a mãe vai deixar de executar para poder acompanhar a criança nas consultas médicas, ao papel do pai que vai ser modificado, incluindo atividades que antes não eram de sua competência, à perda do ambiente domiciliar para permanecer longos períodos em clínicas ou hospitais, à perda da rotina infantil, à falta das idas regulares à escola, dos jogos frequentes com 
os amigos e, inclusive, ao luto pelo corpo infantil e viçoso, que vai sofrer modificações com as sessões de radioterapia ou quimioterapia.

Esse processo de luto e a elaboração dessas perdas provisórias são importantes para a eficiente assimilação da nova condição familiar. Durante esse período os pais podem ir elaborando essas perdas e admitindo a realidade do câncer como doença, o que vai auxiliar eles a estarem em plenas condições para se envolverem no processo e assumirem a função de colaboradores (Menezes et al., 2007). A colaboração dos pais/cuidadores, além do acompanhamento do tratamento, é a de dar continência a criança e auxiliá-la na adaptação a nova condição, permitindo que a mesma fale sobre seus sentimentos e medos; e que depois possa se reinserir com eficiência na escola e no grupo de amigos, apesar de estar fisicamente mudado.

Em alguns momentos, as consequências sociais e psicológicas do câncer infantil podem ser mais debilitantes que a própria doença física (Menezes et al., 2007; Patistea, 2005). Para evitar que tais momentos debilitantes sejam catastróficos para a criança, é essencial que esta esteja amparada por uma rede de apoio que inclui além de médicos, voluntários, enfermeiros e psicólogos, aqueles que a constituíram: a sua família.

Para os familiares assumirem a posição de cuidadores da criança de maneira plena, eles precisam desfrutar de boas condições que os capacitam a se envolverem no enfrentamento da doença. Entretanto, os familiares, frequentemente, se deparam com a situação de procurarem poupar a criança do excesso de sofrimento, sobrecarregando eles mesmos com um sofrimento psíquico que repercute por toda a organização familiar (Menezes et al., 2007).

Reconhecendo, assim, que as muitas implicações sociais e psicológicas do câncer infantil podem até mesmo serem mais exaustivas do que a própria doença física (Patistea, 2005), fica claro a importância da repercussão da doença em todo o sistema familiar, que pode ou não auxiliar no enfrentamento da situação. $\mathrm{O}$ câncer infantil gera sofrimento psíquico não somente à criança doente, mas também na sua família, grupo de apoio fundamental para sua recuperação que pode iniciar um processo de desestruturação.

Considerando a importância do tema, o presente estudo teve como objetivo geral compreender qual é a significação que os familiares/ cuidadores de crianças diagnosticadas com câncer atribuem às relações entre esse diagnóstico e a sua dinâmica familiar.

\section{Método}

Para alcançar o objetivo proposto, optou-se pela realização de um estudo exploratório/descritivo, de abordagem qualitativa. Entende-se que o viés qualitativo, nesse âmbito, é o que melhor serve para a análise das vivências subjetivas dos indivíduos entrevistados. Conforme Chizzotti (1998), essa modalidade metodológica prioriza a consideração dos aspectos singulares e complexos da vida humana, remetendo aos significados que os sujeitos dão às suas ações e relações.

Desde o começo do trabalho de campo, todas as impressões, contradições e questões suscitadas no contexto da pesquisa foram registradas em um diário de campo. Segundo as pontuações de Minayo (1996), tal diário é um acervo de impressões e notas sobre as falas, comportamentos e relações, no qual devem constar ambivalências e contraditoriedades observadas. O uso desse instrumento, portanto, complementou os dados oriundos dos demais instrumentos de pesquisa, favorecendo a qualidade e a profundidade das análises.

Ainda, foram utilizadas técnicas de entrevistas semi-estruturadas e grupos de discussões, constituídos por familiares/cuidadores, acompanhantes das crianças e adolescentes internadas em um hospital público. As entrevistas foram utilizadas como instrumento de coleta de dados em função da pressuposição de que elas possibilitam a expressão e comunicação fidedignas dos informantes acerca de suas experiências, representações, concepções e ideias (Chizzotti, 1998). Ainda, o formato da entrevista utilizado nessa pesquisa foi semi-estruturado, posto que a característica de flexibilidade desse tipo de entrevista permite que o campo da mesma seja constituído por variáveis da personalidade do entrevistado, retratando suas experiências, concepções, atitudes e comportamentos (Bleger, 1980/2007).

Os grupos de discussões complementaram as entrevistas, pois neles o papel prioritário foi desempenhado pelas opiniões, relevâncias e valores dos seus componentes. Os grupos, graças à interação dos seus membros, possibilitaram que 
fossem visualizadas novas formas de interpretação da problemática abordada (Jovchelovitch, 2000).

Participaram da pesquisa familiares/cuidadores que residissem com a criança/adolescente, quando fora do ambiente hospitalar, na cidade de Santa Maria, ou que viessem ao hospital durante o período de coleta de informações. Não houve a delimitação de um número prévio de sujeitos participantes da pesquisa, sendo a amostra condizente com a disponibilidade dos participantes e seu limite definido por meio do critério de saturação da amostra (Moraes, 2003), que considera a finalização da coleta de informações no momento em que dados novos não acrescentam informações relevantes para o tema pesquisado.

Dessa forma, foram realizados três grupos de discussão, compostos por um coordenador do grupo e um auxiliar. Após a discussão nos grupos, os familiares/cuidadores foram convidados a participar de entrevistas individuais. Houve a tentativa de agendamento de entrevistas individuais com os dez cuidadores que participaram dos grupos. Contudo, aceitaram participar de tais entrevistas três indivíduos. Não foi possível contato posterior com quatro desses sujeitos. Os outros três demonstraram comportamento esquivo à abordagem dos pesquisadores, mostrando-se indisponíveis pela expressão direta de sua vontade ou apenas fugindo do contato com os pesquisadores. No entanto, pensou-se ser pertinente para os objetivos do trabalho considerar-se, para fins de análise, a recusa dos indivíduos em participar das entrevistas individuais. Dessa forma, realizou-se o registro, no diário de campo, dos comportamentos e falas dos sujeitos que se recusaram a participar das entrevistas, conforme as afirmações supramencionadas por Minayo (1996).

Nas entrevistas e nos grupos foram abordados os seguintes pontos identificados como eixos norteadores do trabalho: a criança antes do diagnóstico e depois do diagnóstico; a situação familiar antes e depois do diagnóstico; a doença da criança; o momento do diagnóstico; o processo de comunicação da doença dentro da família; os papéis desempenhados pelos progenitores/cuidadores antes e depois do diagnóstico; o cotidiano familiar no passado e no presente; o relacionamento do casal parental antes da doença e no momento atual. Após o consentimento dos indivíduos, as entrevistas e os grupos foram gravados em gravador digital e transcritos na íntegra, para posterior análise.
As informações assim obtidas foram tratadas de acordo com a análise de conteúdo (Bardin, 1977), método de reconhecida importância nas pesquisas qualitativas, uma vez que possibilita a visualização dos diferentes sentidos (manifestos e latentes) das falas dos sujeitos da pesquisa (Minayo, 1996). Após a leitura flutuante do material coletado, foram categorizados os tópicos emergentes segundo os critérios de relevância e repetição (Turato, 2003). Dessa forma, os resultados obtidos foram interpretados, promovendo-se inferências e interpretações relacionadas com a fundamentação teórica.

Nas transcrições, os nomes dos entrevistados foram substituídos pelos seguintes códigos: $\mathrm{G}$ (refere-se às entrevistas realizadas em grupos), $\mathrm{E}$ (refere-se às entrevistas individuais) e $\mathrm{R}$ (refere-se aos relatos efetuados pelo pesquisador no diário de campo). As falas dos participantes foram, assim, identificadas pelas letras E ou G, seguidas pela palavra "Familiar" e por letra alfabética que identifica os diferentes sujeitos, por exemplo: E, Familiar A.

Foram seguidos os preceitos da Resolução de 196/96 do Conselho Nacional de Saúde, que normatizam as condições da pesquisa que envolvem seres humanos, considerando a ética, a preservação da identidade dos participantes e não oferecendo riscos ou perdas para esses. As atividades de campo previstas em tal pesquisa apenas foram realizadas após aprovação do comitê de ética da instituição em que foi realizada.

\section{Resultados e discussão}

Participaram das entrevistas e grupos apenas mães de crianças e adolescentes. A única figura masculina com que foi possível o contato não aceitou participar da pesquisa, sendo sua recusa ilustrada sob forma de relato. Assim, a partir da análise dos dados, emergiram algumas categorias e subcategorias significativas relacionadas ao tema proposto neste artigo. São elas:

\section{Casa versus Hospital}

Essa categoria caracteriza-se pela contraposição entre as representações do ambiente doméstico e o hospitalar. Evidencia-se a concordância com os apontamentos de Angerami-Camon 
(2006) e Botega (2006), posto que o ambiente hospitalar parece ser significado pelos cuidadores como espaço promotor de despersonalização do paciente e do familiar/cuidador, na medida em que implica a assunção de um papel passivo às regras e horários institucionais.

"Em casa, a hora que eles [as crianças] pedem a gente pegaefaz: Aquinão, aqui tem hora" (G, Familiar A).

As falas também retomam a noção de que existe um mal-estar no compartilhamento do cuidado com a equipe, inerente ao ambiente hospitalar (Bousso \& Angelo, 2001; Chiattone, 2003b; Silva et al., 2006). Tal mal-estar mostra-se arraigado ao contato com um mundo de linguajar específico, com normas e regras que limitam a autonomia parental (Silva et al., 2006).

"Ai teve um dia que eu tive a impressão que eles [os médicos responsáveis pelo caso estavam me enrolando, sabe?’ (G, Familiar G).

As falas parecem retratar, portanto, certo sentimento de impotência, remetendo à associação do espaço hospitalar com a noção de aprisionamento, enquanto a casa poderia representar a liberdade, o aspecto saudável da vida.

"Claro, ele [a criança enferma] não gosta de estar preso, não gosta de estar preso, tudo solto em casa" (E, Familiar H).

Dessa forma, retornar para a casa, ao longo da hospitalização e tratamento do filho, é um movimento que parece implicar sofrimento. A ausência do filho em casa pode remeter à lembrança da doença.

"Eu fiquei dois meses sem ir pra casa, eu ficava na casa da minha mãe. Então nem meu marido ia, pelo choque de ver o quarto dele, as roupas dele, a cama dele, essas coisas" (E, Familiar J).

\section{Mudanças e desestruturação familiar}

Consoante às ideias de Kovács (2003), a fala dos participantes da pesquisa acerca das consequências da doença e do tratamento com relação à rotina da família parece ser caracterizada por uma série de alterações.
"Mas que a gente e a estrutura familiar balançam, balançam. Com certeza, muda tudo. Tu não sabe como está tua casa, eu mesmo faz um mês que estou aqui, nem se?’ (G, Familiar A).

Assim, ficam evidentes as percepções de mudanças que tanto concernem aos vínculos afetivos que unem os membros da família, quanto à organização das tarefas da rotina. A modificação de papéis, ainda que possa promover desavenças, pode também inovar ao provocar novos padrões de comportamento, sendo que normalmente o restabelecimento da criança doente é o fator que mais mobiliza a família nesse momento (Crepaldi, 1998). A doença pode, assim, ser um evento de união e reconciliação familiar (Beck \& Lopes, 2007a, Chiattone, 2003b):

"a gente [o casal] sempre se reveza assim que dá. Mas assim, melhor impossivel a relação dos três [casal e filho], digamos, sabe?” (E, Familiar J).

Por outro lado, os problemas de relacionamento podem serincrementados com o aparecimento da doença na família (Chiattone, 2003b):

"eu brigo [com o pai do filho], eu chamo, eu digo que é covarde, en digo que sou en que aguento tudo sozinha, sabe? Ele chora" (E, Familiar E).

As repercussões da situação de doença também dizem respeito à estruturação financeira da família (Quintana et al., 2009; Silva et al., 2009).

É que agora o médico sugeriu transplante [para o filho doente] e ele vai ter que ficar um ano internado no CTMO. Meu marido perdeu o emprego que ele tinha e agora vamos vir morar aqui em Santa Maria, a familia toda, e em meu filho de um ano está saindo $o$ dentinho (R, Familiar B).

As falas remetem à existência de um movimento de busca de preservação da integridade familiar diante da crise representada pelo adoecimento, por meio da organização de alterações na rotina e nas relações (Bousso \& Angelo, 2001; Quintana et al., 2009). As mudanças referidas parecem ter a intenção de manutenção da unidade e coesão familiar. No entanto, nem sempre se mostram eficazes. 


\section{Papel materno}

É interessante notar que a grande maioria dos cuidadores entrevistados, presentes como acompanhantes na internação hospitalar, constituía-se de mulheres. Nesse sentido, evidencia-se o papel materno como outorgado histórica e culturalmente (Costa, 1983). Partindo do pressuposto que é da mãe, historicamente, a responsabilidade pelo ambiente doméstico e a função de zelar pelos filhos, evidencia-se na fala dos participantes a obrigatoriedade de assunção de tal papel, em detrimento de qualquer outro.

"Porque eu, se tivesse que abandonar marido, ou casa, eu abandonaria por causa dela, né? [...] eu sempre digo, sabe, primeiro lugar pra mim é meus filhos" (G, Familiar G).

Nesse contexto, aparece a percepção de que ninguém está à altura da mãe para cuidar e proteger seu filho (Beck \& Lopes, 2007b). Portanto, há um cenário que envolve completa dedicação aos filhos doentes, parecendo configurar relações que envolvem extremo zelo e proteção, algumas até com características simbióticas.

"Eu acho que às vezese éproteção demais, en sei que a mãe sufoca, né?" (G, Familiar E).

No contexto apresentado, a vida das mães aparece ressignificada. As falas, dessa forma, mostram-se ambivalentes, com conteúdos que ora remetem à vida e ora remetem à morte (Monteiro et al., 2008).

Então o meu tava três dias em casa com febre, eu não queria trazer [...] não queria vir pra cá no hospital por causa do pequeno, né? Porque chegou um ponto dele pedir: "mãe, eu não aguento mais", até que [...] depois o filho morre e a culpa é minha, porque aí eu vou sofrer mais ainda, né? (G, Familiar B).

Pode-se pensar, a partir da fala anterior, na existência da sensação de impotência diante da doença do filho, ao mesmo tempo em que aparece a fantasia de atribuição da cura às ações da mãe. Mediante tal confusão de percepções e sentimentos, parece emergir a sensação de desamparo.
"Tu se sente sozinha no mundo, porque não tem... Não adianta, nem que tu queira que alguém venha, mas não tem, no caso, por eles serem pequenos, né? $\mathrm{E}$ ai vai cansando" (G, Familiar L).

\section{As mães na ala e suas inter-relaçóes}

Salienta-se, no grupo pesquisado, a relevância das relações estabelecidas entre os cuidadores de diferentes crianças no ambiente hospitalar. Tal relação parece passar por processos identificatórios, que implicam também a construção de uma espécie de disputa.

\section{Identificaçáo}

O contato com os demais cuidadores parece, assim, minimizar o sentimento de solidão e desamparo ao longo da hospitalização, a partir da construção de um espaço em que os sentimentos possam ser compartilhados por meio da verbalização (Ortiz \& Lima, 2007). Nesse ínterim, pode ser estabelecida uma relação autêntica de cuidado, facilitando o tratamento (Monteiro et al., 2008).

Então pra quem já tá muito tempo aqui, tu vai explicando o que acontece. Tem mães que não dão a sorte. Já foi crianca bastante, mas acho que a gente vai explicando assim, é isso, é isso, que é até pra tranquilizar, né? Porque eu mesmo passei por isso quando entrei aqui (G, Familiar L).

Contudo, percebe-se a concepção da necessidade de parcimônia no compartilhamento de informações por parte dos familiares/cuidadores já instalados no hospital com os familiares de crianças e adolescentes recém-internados. Algumas pessoas referem “escolher" que informações devem ser repassadas, já que o início da internação pode dizer respeito a uma situação de vulnerabilidade emocional. Assim, tal cuidado pode ser entendido como um meio de proteção, evitando-se falar sobre as possibilidades negativas e penosas do tratamento e internação com os recém-chegados.

"Como eu te digo, com as mães aquié triste... Tu chega, porque se tu vai conversar, desabafar com uma mãe, tu vai amedrontar ela" (E, Familiar E). 


\section{Competiçáo}

Também parecem ser construídas, principalmente entre as mães cuidadoras, certas características na relação entre elas, que implicam uma disputa. Como incomoda as mães a ausência de apetite nos filhos causada pelo tratamento (Beck \& Lopes, 2007b), foi possível notar ao longo dos grupos certa rivalidade no apontamento do exercício da função materna de nutriz.

Agora quando tá com fome... porque ele é gordo, tem 9 anos e tá com $49 \mathrm{~kg}$, né? (G, Familiar B).

E o meu! Vou te dar uma base. O meu, que não tomava corticoide, antes comia dois ovos e um bifão desse tamanho e um pão desse tamanho com manteiga e café. E tem 3 anos, com 21,8 kg tava hoje! (G, Familiar A).

As falas sugerem a existência de uma configuração na relação das mães que vai ao encontro de um reasseguramento sobre o exercício da função materna de forma bem-sucedida. Assim, ao exporem o status nutricional dos filhos (considerado aqui como medida de saúde), as mães parecem estar reiterando o seu poder de manutenção da saúde dos filhos por meio de um viés comparativo.

\section{Rede de apoio}

Os participantes da pesquisa parecem entender a importância, de forma inequívoca, de uma rede de apoio que possa sustentar a ausência dos cuidadores principais no ambiente doméstico. Colocam como participantes desta rede os pais, os filhos sadios e demais familiares e amigos.

\section{Papel paterno}

O pai é evidenciado como uma figura coadjuvante nos cuidados prestados ao filho. Cabe a ele a assunção de funções no espaço público (Costa, 1983), a saber, a provisão de recursos financeiros (Chiattone, 2003b; Silva et al., 2009).

"A vida é assim. Meu marido trabalha pra poder mandar as coisas, né? A gente gasta aqui também" (G, Familiar B). "E meu marido não pode estar aqui, porque ele trabalha e alguém precisa enviar o sustento, dai eu fico sempre sozinha. E minha mãe também trabalha, não pode vir aqui sempre" (R, Familiar D).

A divisão de papéis nesse formato, no entanto, tem um preço. O distanciamento do casal parece onerar o cuidador principal, acentuando sentimentos de abandono e desamparo. Tal situação é compreendida por alguns como necessária e inerente às contingências, sendo os pais valorizados pelo cumprimento de suas atribuições.

"Então aí a gente vai falar tudo pros pais, mas depois a gente entra na realidade que, se não é ele, o que vai ser de nós?’ (G, Familiar L).

Aparecem constituições de dinâmicas familiares variadas. Há aquelas nas quais os pais são participativos ao longo da internação, embora nem sempre possam estar presentes. Por outro lado, em outras famílias, o papel paterno mostra-se unicamente vinculado ao suprimento das necessidades materiais, havendo lacunas no âmbito afetivo.

"E o pai dela também, né? Ele tá sempre por dentro, tá sempre acompanhando, sempre querendo saber de tudo. Então, graças a Deus eu não tenho dificuldade, que tem que entender, né?’' (G, Familiar G).

Ele não quer vir. Em casa ele vê e tudo, se eu precisar de dinbeiro, se eu precisar de alguma coisa ele vem na porta do hospital, mas ele, ele disse que não quer ver o filho dele [...]. Quando a gente vai pra casa com o [filho doente], e o [filho doente] far as quimios, fica abatido assim, ó. Ele olha, cumprimenta o filho, mas ele procura não ficar perto dele (E, Familiar E).

\section{Os filhos sem diagnóstico de câncer}

Os irmãos dos filhos doentes aparecem em posição de destaque na percepção dos entrevistados. Embora entendam que devem priorizar os cuidados aos filhos doentes, responsabilizam-se pelas repercussões geradas por essa situação em relação aos filhos que permanecem em casa. Concordando com Crepaldi (1998), parece haver uma sensação de perda de filiação, mediante a impossibilidade de manter a coesão familiar. 
"Não éfácil, né? Porque, bem dizer, a gente abandona a casa. Mas é que tem que entender que ela precisa mais de mim do que ele" (G, Familiar G). "Eu tenho uma menina de 9 que, quando surgiu a doença dele, ela mamava no peito. Hoje em dia ela é carente" (G, Familiar L).

Tal condição parece gerar a sensação de impotência e o sentimento de que os cuidadores estão sendo negligentes e irresponsáveis (Crepaldi, 1998), culpabilizando-se por possíveis falhas no desenvolvimento dos demais filhos (Klassmann et al., 2008).

Meu guri me cobra muito, esse rapaz de 17 anos, que fez 17 anos. Ele fica furioso quando eu venho pra cá fazer consulta. Eu chego em casa, ele me agride, me dir: "não toca em mim". Mas ele me xinga, sabe? Eu acho que na fase que ele mais precisou, que é na fase da adolescência, ele parou de estudar por conta, não estuda mais ( $\mathrm{G}$, Familiar $\mathrm{E})$.

Há relatos de reações de desprezo e ciúmes por parte do filho sadio, provocado por ressentimento e inveja a respeito do excesso de zelo desvelado ao irmão doente (Pedrosa \& Valle, 2000).

"Só de vez em quando ele dir.pra mim assim: 'éu vou ficar doente pra ti me cuidar igual [ao filho doente]" (E, Familiar E).

Fica implícito, dessa forma, o entendimento de que o filho que permanece em casa sente-se abandonado e desamparado, o que implica o entendimento de certa falência da função parental de cuidado e proteção.

\section{Demais amigos, parentes}

As demais pessoas e os familiares vinculados ao cuidador principal parecem assumir função de suporte afetivo e apoio em relação às tarefas domésticas (Beck \& Lopes, 2007a).

"A minha mãe ta lá, ó, olha pra mim, limpa a casa e tudo, mas tu não sabe se a casa está do jeito que tu gosta” (G, Familiar A).

Salientam-se, nesse caso, as dificuldades na delegação de funções para outras pessoas, tanto em relação aos cuidados hospitalares, quanto em relação às tarefas da vida doméstica (Beck \& Lopes, 2007b). Conforme afirmam os autores, essa postura pode ser geradora de sobrecarga para as mães, na medida em que dificulta uma divisão mais equitativa de papéis.

Além disso, a distância física dos demais familiares e amigos parece ser vislumbrada como um obstáculo. No entanto, o simples contato telefônico pode ser valorizado e compreendido como a forma viável de auxílio em determinados momentos.

Então, às vezes tu nem percebe, mas a pessoa está te passando aquela energia pelo telefone, coisa assim. E as visitas vêm também quando dá, porque é longe, né? Todo mundo trabalha, as famílias trabalham (G, Familiar K).

\section{Consideraçóes finais}

As considerações tecidas neste ensaio remetem a questionamentos que aludem à pluralidade de formas em que a família organiza-se para dar conta das crises que a acometem. Tais formas dizem respeito aos papéis assumidos pelos diversos membros da família. Neste estudo, destaca-se o papel materno como o que mantém e assegura a coesão familiar e a integridade dos filhos, tanto psíquica quanto física. A responsabilização por tal integridade, mediante a situação de doença, parece gerar carga intensa de sofrimento. Assim, a assunção do papel de protetor coloca um paradoxo, que aqui se nomeia "paradoxo do desamparo". Apesar do conhecimento do senso comum de que a doença é algo que diz respeito à ordem do incontrolável, ainda assim, para os entrevistados, parece haver um esforço no sentido de exercer controle sobre a situação de adoecimento. Diante da impossibilidade disso, emergem, além dos sentimentos de impotência e culpa, situação de sobrecarga implicada na posição onipotente em que se coloca o cuidador principal, culminando no sentimento de desamparo.

Os familiares/cuidadores pesquisados parecem entender que é sua função a oferta de espaço de continência à criança. Contudo, para que tais sujeitos possam auxiliar seus filhos na adaptação à nova condição, devem permitir que eles falem sobre seus sentimentos e medos. Dessa forma, seria necessário que as famílias pudessem assimilar e elaborar as perdas provisórias presentes no processo de adoecimento 
para poderem estruturar-se à nova configuração familiar. Sob esse prisma, deve-se proporcionar a apropriação, pelo paciente e pela família, das situações vividas a partir da doença e do tratamento. Assim, para que os pais possam facilitar o processo de luto de seus filhos, é necessário que eles mesmos passem por tal processo, permitindo-se dar sentidos para as vivências da doença e do tratamento. Os resultados desse trabalho lançam, portanto, um desafio aos profissionais da área da saúde e, em especial, aos envolvidos na área psi: sermos agentes facilitadores em tal processo.

\section{Agradecimentos} financeiro.

Ao CNPq e FIPE, pelo apoio e auxílio

\section{Referências}

Angerami-Camon, V. A. (2006). O psicólogo no hospital. In V. A. Angerami-Camon. Psicologia hospitalar teoria e prática (pp. 25-28). São Paulo: Pioneira Thomson Learning.

Bardin, L. (1977). Análise de conteúdo. Lisboa: Edições 70.

Beck, A. R. M., \& Lopes, M. H. B. M. (2007a). Cuidadores de crianças com câncer: Aspectos da vida afetados pela atividade de cuidador. Revista Brasileira de Enfermagem, 60(6). Recuperado em 15 out 2009, em www.scielo.br

Beck, A. R. M., \& Lopes, M. H. B. M. (2007b). Tensão devido ao papel de cuidador entre os cuidadores de crianças com câncer. Revista Brasileira de Enfermagem, 60(5). Recuperado em 15 out 2009, em www.scielo.br

Bleger, J. (2007). Temas de psicologia: Entrevista e grupos. São Paulo: Martins Fontes. (Originalmente publicado em 1980).

Botega, N. J. (2006). Reação à doença e à hospitalização. In N. J. Botega. (Org.). Prática psiquiátrica no hospital geral: Interconsulta e emergência (pp. 49-66). Porto Alegre: Artmed.
Bousso, R. S., \& Angelo, M. (2001). Buscando preservar a integridade da unidade familiar: A família vivendo a experiência de ter um filho na UTI. Revista da Escola de Enfermagem da USP, 35(2). Recuperado em 15 out 2009, em www.scielo.br

Chiattone, H. B. C. (2003a). A criança e a hospitalização. In V. A. Angerami-Camon (Org.). A psicologia no hospital (pp. 23-99). São Paulo: Pioneira Thomson Learning.

Chiattone, H. B. C. (2003b). A criança e a morte. In V. A. Angerami-Camon (Org.). E a psicologia entrou no hospital (pp. 69-146). São Paulo: Pioneira Thomson Learning.

Chizzotti, A. (1998). Pesquisa em ciências humanas e sociais. São Paulo: Cortez.

Costa, J. F. (1983). Ordem médica e norma familiar. Rio de Janeiro: Edições Graal.

Crepaldi, M. A. (1998). Famílias de crianças hospitalizadas: Os efeitos da doença e da internação. Revista Ciência \& Saúde, 17, 82-92. Recuperado em 15 out 2009, em www.labsfac.ufsc.br/documentos/ familiasCriancasHospitalizadas.pdf

Instituto Nacional do Câncer-INCA. Particularidades do câncer infantil. Recuperado em 28 mar. 2008, em http://www.inca.gov.br/conteudo_view. asp?ID $=125$

Jovchelovitch, S. (2000). Representações sociais e esfera pública: A construção simbólica dos espaços públicos no Brasil. Petrópolis: Vozes.

Klassmann, J., Kochia, K. R. A., Furukawa, T. S., Hiragashi, I. H., \& Marcon, S. S. (2008). Experiência de mães de crianças com leucemia: Sentimentos acerca do cuidado domiciliar. Revista da Escola de Enfermagem da USP, 42(2). Recuperado em 15 out 2009, em www. scielo.br

Kovács, M. J. (2003). Educação para a morte: Desafio na formação de profissionais de saúde e educação. São Paulo: Casa do Psicólogo; FAPESP.

Menezes, C., Passareli, P., Drude, F., \& Santos, M. (2007). Câncer infantil: Organização familiar e doença. Revista Mal-Estar e Subjetividade, 7(1), 191-210. Recuperado em 15 out 2009, em http://pepsic.bvspsi. org.br/pdf/malestar/v7n1/11.pdf 
Minayo, M. C. S. (1996). O desafio do conhecimento: Pesquisa qualitativa em saúde. São Paulo: Hucitec-Abrasco.

Monteiro, C. F. S., Veloso, L. U. P., Sousa, P. C. B., \& Morais, S. C. R. V. (2008). A vivência familiar diante do adoecimento e tratamento de crianças e adolescentes com leucemia linfóide aguda. Cogitare Enfermagem, 13(4), 484-489. Recuperado em 15 out2009, em http://ojs.c3sl.ufpr.br/ojs2/index.php/ cogitare/article/viewFile/13104/8863

Moraes, R. (2003). Uma tempestade de luz: Uma compreensão possibilitada pela análise textual discursiva. Ciência \& Educação, 9(2), 191-211.

Nascimento, L. C., Rocha, S. M. M., Hayes, V. H., \& Lima, R. A. G. (2005). Crianças com câncer e suas familias. Revista da Escola de Enfermagem da USP, 39(4), 469-474. Recuperado em 15 out 2009, em www.scielo.br

Organização Mundial de Saúde - OMS. Cancer. Recuperado em 27 abr. 2008, em http://www.who. int/hpr/NPH/docs/gs_cancer.pdf

Ortiz, M. C. A., \& Lima, R. A. G. (2007). Experiências de familiares de crianças e adolescentes, após término do tratamento contra câncer: Subsídios para o cuidado de enfermagem. Revista Latino-Americana de Enfermagem, 15(3). Recuperado em 15 out 2009, em www.scielo.br

Parkes, C. M. (1998). Luto: Estudos sobre a perda na vida adulta. São Paulo: Summus.

Papalia, D. E. (2006). Desenvolvimento humano. 8. ed. Porto Alegre: Artmed.

Patistea, E. (2005). Description and adequacy of parental copingbehaviors in childhoodleukaemia. International Journal of Nursing Studies, 42, 283-296.

Pedrosa, C. M., \& Valle, E. R. M. (2000). Ser irmão de criança com câncer: Estudo compreensivo. Pediatria, 22(2), 185-194.

Quintana, A. M., Arpini, D. M., Pereira, C. R. R., \& Santos, M. S. (2009). O acompanhante e a equipe de saúde na hospitalização de crianças. In A. C. G. Dias (Org.). Psicologia \& saúde: Pesquisas e reflexões (pp. 41-62). Santa Maria, RS: Ed. da UFSM, 2009.
Silva, F. A. C., Andrade, P. R., Barbosa, T. R., Hoffmann, M. V., \& Macedo, C. R. (2009). Representação do processo de adoecimento de crianças e adolescentes oncológicos junto a familiares. Escola Anna Nery Revista de Enfermagem, 13(2). Recuperado em 15 out 2009, em http://www.eean.ufrj.br/revista_ enf/20092/artigo\%2012.pdf

Silva, L. C., Weiss, E. W., Bernardes, D. B., \& Souza, A. I. J. (2006). Hospitalização e morte na infância:Desafios das famílias. Família, Saúde e Desenvolvimento, 8(1). Recuperado em 15 out 2009, em http:// ojs.c3sl.ufpr.br/ojs2/index.php/refased/article/ view/8024/5651

Turato, E. R. (2003). Tratado da metodologia da pesquisa clínico-qualitativa. Petrópolis: Vozes.

Valle, E. R. M., \& Françoso, L. P. C. (1999). Psicooncologia pediátrica: Vivências de crianças com câncer. Ribeirão Preto, SP: Scala.

Valle, E. R. M., \& Mello, L. L. (1999). Equipe de enfermagem, criança com câncer e sua família: Uma relação possível. Pediatria Moderna, 35(12), 970-972.

Wanderbroocke, A. C. N. S. (2005). Cuidando de um familiar com câncer. Psicologia Argumento, 23(41), 17-23.

Recebido: 02/02/2010

Received: 02/02/2010

Aprovado: 19/05/2010

Approved: 05/19/2010 